\title{
Characterization of high pressure jet-induced fat-protein complexation
}

\author{
G. Lewis, (1) J. N. Coupland, and F. M. Harte* (i) \\ Department of Food Science, The Pennsylvania State University, University Park 16802
}

\section{ABSTRACT}

High-pressure-jet (HPJ) processing of various dairy systems has been shown to disrupt fat droplets and casein micelles and cause a strong association between fat and casein proteins. The present work seeks to better describe this association between fat and casein using a model milk formulated from confectionary coating fat $(3.6 \% \mathrm{wt} / \mathrm{wt})$, micellar casein $(3.4 \% \mathrm{wt} / \mathrm{wt})$, and water $(93 \% \mathrm{wt} / \mathrm{wt})$, which was then pasteurized, homogenized, and then either HPJ-treated (400 MPa) or not (non-HPJ-treated, control). Upon ultracentrifugation, fat in the non-HPJ-treated model milk creamed due to its low density. In the HPJ-treated model milk, fat precipitated with protein into a thick bottom layer upon ultracentrifugation, reflecting a strong association between protein and fat. Differential scanning calorimetry (DSC) and time-domain nuclear magnetic resonance of the non-HPJ-treated model milk revealed fat in 2 physical states: (1) fat that is physically similar to the bulk fat and (2) fat that was in smaller droplets (i.e., homogenized) and crystallized at a lower temperature than the bulk fat. In contrast, DSC of HPJtreated model milks supported the presence of fat in 3 states: (1) fat that is physically similar to the bulk fat, (2) fat in small droplets that required substantial supercooling beyond the non-HPJ-treated model milk to crystallize, and (3) fat in such small domains that it crystallizes in a less stable polymorphic form than the non-HPJ-treated model milk (or does not crystallize at all). The state of fat within the HPJ-treated model milk changed minimally with acidification, indicating that the association is not dependent on the charge on the casein. Cryogenic transmission electron microscopy (Cryo-TEM) of the non-HPJ-treated model milk revealed uniform casein micelles, which likely adsorbed to the surface of fat globules post-homogenization. In contrast, Cryo-TEM of the HPJ-treated model milk revealed a porous protein aggregate that likely had dispersed fat throughout. Together, these results sug-

Received September 7, 2021.

Accepted November 12, 2021

*Corresponding author: fmh14@psu.edu gest that HPJ treatment causes fat to be entrapped by casein proteins in very small domains.

Key words: high pressure, lipids, casein, calorimetry, nuclear magnetic resonance

\section{INTRODUCTION}

In raw, non-homogenized milk, casein micelles and milk fat globules exist primarily as separate colloidal particles dispersed in the serum. A native milk fat globule membrane, rich in polar lipids and glycoproteins, surrounds the milk fat globule (Obeid et al., 2019). Most milk sold commercially is homogenized to prevent fat separation (i.e., creaming; Harte, 2016). Conventional homogenization involves the feeding of a liquid sample through flow restriction (i.e., stages) at pressures ranging from 10 to $30 \mathrm{MPa}$ (Datta and Tomasula, 2015). Most industrial-scale homogenizers contain 2 stages to prevent the formation of fat clusters (Walstra, 1999), with the second stage operating at back pressures of 10 to $20 \%$ of the first stage (Harte, 2016). Upon conventional homogenization, the native milk fat globule membrane is disrupted as the particle size of the milk fat globules is reduced, causing an overall increase in surface area and allowing other proteins to adsorb to the surface of fat droplets (Datta and Tomasula, 2015). Cano-Ruiz and Richter (1997) found that, in homogenized milk, the proteins adsorbed to the surface of milk fat globules consisted of $\alpha$-LA, $\beta$-LG, caseins ( $\sim 70 \%$ of proteins on the surface of the fat globules), and native membrane proteins. The composition of this post-homogenization membrane can be altered by varying processing conditions including homogenization pressure (Wang et al., 2019) and pasteurization temperature (Cano-Ruiz and Richter, 1997; Lee and Sherbon, 2002; Wang et al., 2019). The components adsorbed to the surface of the milk fat globules are important for determining milk fat stability, digestibility (Tunick et al., 2016), and functionality in specific dairy products (e.g., cheese; Rudan et al., 1998).

Ultra-high-pressure homogenization (UHPH) has even more significant effects on the components adsorbed to the surface of milk fat globules (Zamora et al., 2012; Kiełczewska et al., 2021). Ultra-high-pressure homogenizers, operating at pressures of 100 to $400 \mathrm{MPa}$, 
have 1 or 2 abrasion-resistant valves that cause severe shear, cavitation, turbulence, friction, and heat to fluid samples (Harte, 2016). Casein micelles and fat globules are disrupted with UHPH, especially at higher processing pressures (100-300 MPa; Zamora et al., 2012). In addition, Zamora et al. (2012) found that in UHPHtreated milk, casein micelles were adsorbed at the surface of the milk fat globules to a lesser extent than in traditional homogenization-pasteurization. Instead, casein molecules, released through the UHPH-induced partial disruption of casein micelles, were adsorbed to the surface of the milk fat globules.

Although casein micelles are natural carriers of hydrophobic small molecules in fluid milk (Cheema et al., 2017), UHPH-induced disruption of casein micelles has been shown to more effectively encapsulate hydrophobic compounds in the form of micro- or nanoparticles (Ranadheera et al., 2016). Similarly, Haham et al. (2012) found that UHPH-induced (155 MPa) disruption and subsequent reformation of casein micelles encapsulated vitamin $\mathrm{D}_{3}$, enhancing its stability by protecting against heat- and storage-based degradation.

High-pressure-jet (HPJ) processing pressurizes a liquid sample up to $600 \mathrm{MPa}$ before forcing it through a single restriction to flow in the form of a diamond, sapphire, or ruby nozzle. This process creates severe sample turbulence, shear, and friction at the nozzle and has been shown to thoroughly disrupt casein micelles (Hettiarachchi et al., 2018). Furthermore, HPJ-induced co-precipitation of fat and casein has been noted in a range of dairy systems including whole milk (Tran et al., 2018) and ice cream mix (Voronin et al., 2020). This material has been termed a "fat-protein complex," yet not much is known about the microstructure and specific associations between fat and protein in these systems.

The objectives of the present work were to determine the association, crystallization properties, and microstructure of non-HPJ-treated and HPJ-treated model milks. Samples were studied as a function of $\mathrm{pH}$ (7.0-4.5) to determine whether the fat-protein complex depended on protein charge. We hypothesized that following HPJ treatment, fat is encapsulated as very small droplets within a matrix of casein proteins after HPJ-induced casein micelle and fat droplet disruption and reaggregation.

\section{MATERIALS AND METHODS}

\section{Model Milk Formulation}

Micellar casein concentrate (MCC; Leprino Foods), specified to have no less than $86 \%$ protein (dry basis) with a 95:5 casein-to-whey ratio, was combined with a cocoa butter substitute (CBS; hydrogenated palm kernel stearin fraction, PK1000, Cargill) and distilled water to create a "model milk."

To prepare the model milk samples, distilled water $\left(17.7 \mathrm{~kg}\right.$ ) was first heated to $43^{\circ} \mathrm{C}$. At that temperature, MCC $(0.65 \mathrm{~kg})$ and CBS $(0.69 \mathrm{~kg}$, previously held at $80^{\circ} \mathrm{C}$ to eliminate all crystal memory) were added. The model milk was then pasteurized $\left(63^{\circ} \mathrm{C}\right.$ for $\left.30 \mathrm{~min}\right)$ under continuous agitation and homogenized (13.8 MPa, 3.4 MPa; Eaton Corporation). Three different batches were prepared to create triplicate samples. Each batch was separated into a control sample (non-HPJ-treated) and treatment sample (400 MPa HPJ-treated, discussed subsequently). The model milks to be HPJ-treated were stored overnight $\left(4^{\circ} \mathrm{C}\right)$ before HPJ processing.

The composition of the model milk was formulated to be a reasonable model for actual dairy systems, while allowing for simplified quantification using the methods described herein. As HPJ processing has been shown to dissociate casein micelle and to have limited influence on whey proteins (Mohan et al., 2016), MCC was used in the model milk to effectively isolate the casein proteins. The CBS was selected to have a narrow fat crystallization range with a single crystallization peak in its bulk form (Figure 1), allowing for easier characterization than regular milk fat using differential scanning calorimetry (DSC). More specifically, the bulk fat peak in CBS is monomodal and shifts can be easily characterized, unlike the multimodal, broad fat crystallization peaks seen in milk fats (Truong et al., 2014). Distilled water was used instead of skim milk ultrafiltrate or simulated milk ultrafiltrate to minimize the lactose and minerals present in the dried model milk, allowing for the quantification of (mostly) protein and fat with proximate analysis and characterization of fat crystallization (in contrast to lactose crystalliza-

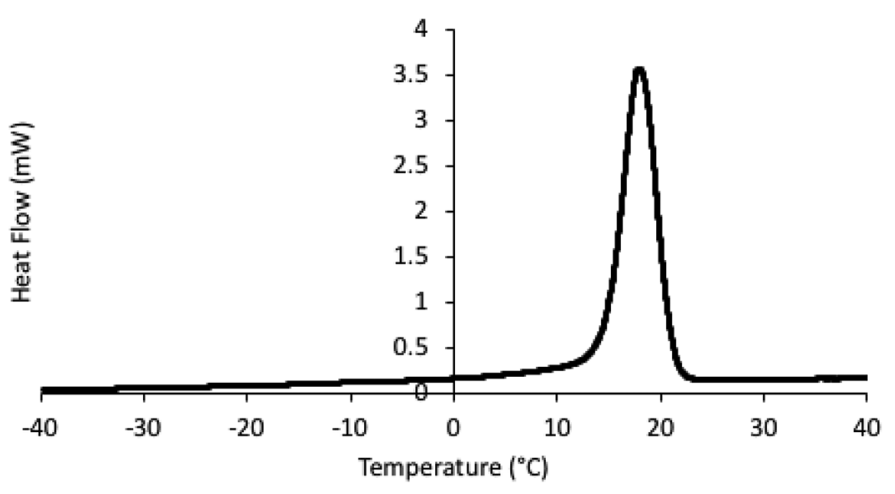

Figure 1. Fat crystallization peak of pure cocoa butter substitute (CBS) as determined by differential scanning calorimetry. This CBS was selected to have 1 crystallization peak (in contrast to typical milk fat). 
tion) with DSC. It should be noted that the use of distilled water might have destabilized the casein micelles slightly before HPJ treatment.

\section{HPJ Processing}

The model milk $\left(4^{\circ} \mathrm{C}\right)$ was continuously fed into a $\mathrm{Hy}-$ perjet 94i-S pump system (Flow Internationals Corp.) using a diaphragm pump (Flojet Duplex II, Xylem). Inside the HPJ, an intensifier pump compressed the fluid to achieve a pressure of $400 \mathrm{MPa}$. The sample then passed through an attenuator that minimized pressure fluctuations and forced through a diamond nozzle (orifice size $=229 \mu \mathrm{m}$ ). At the orifice, the pressurized fluid was released at high velocities ( Mach 3$)$, which aerosolized the sample. The aerosolized sample was then collected into a heat exchanger with a counter-current flow of cold water $\left(\sim 2^{\circ} \mathrm{C}\right)$, which condensed and cooled the sample for collection. At this pressure, the flow rate through the HPJ was $\sim 1.6 \mathrm{~L} / \mathrm{min}$. Sample was discarded for 2 min following initial pressure equilibration, to ensure that all collected sample was HPJ-treated at 400 MPa. A skim milk sample (Penn State Berkey Creamery, University Park, PA) was also HPJ-processed at $400 \mathrm{MPa}$ and collected for microscopy.

\section{pH Adjustments}

Five aliquots $(50 \mathrm{~mL})$ of the non-HPJ-treated and HPJ-treated model milks were separated for $\mathrm{pH}$ adjustments to 7.0, 6.5, 5.5, 5.0, and 4.5. The $\mathrm{pH}$ of each aliquot was adjusted slowly by adding $1 \mathrm{~N} \mathrm{HCl}$ in $\sim 10-\mathrm{uL}$ drops as the aliquots were continuously mixed. Samples were equilibrated at the corresponding $\mathrm{pH}$ for $1 \mathrm{~h}$, and minor $\mathrm{pH}$ readjustments were made if necessary.

\section{Ultracentrifugation}

Model milks (19 g) were ultracentrifuged using a S50A rotor at $100,000 \times g$ for $1 \mathrm{~h}$ at $4^{\circ} \mathrm{C}$ (Sorvall MTX 150 Micro-Ultracentrifuge, ThermoFisher Scientific). Immediately following ultracentrifugation, samples were manually separated into top, middle, and bottom fractions. The middle fraction, containing little solids, was discarded. The top and bottom fractions of each sample, as well as a non-ultracentrifuged sample at $\mathrm{pH}$ 7.0 and $\mathrm{pH} 5.0$ (termed "total" sample), were frozen and freeze-dried for additional analysis.

\section{Proximate Analysis}

Total Solids. The total sample as well as the top and bottom fractions of each sample following ultracen- trifugation was weighed before and after freeze drying to determine total solids as follows (Equation [1]):

Total solids $(\%)=\frac{\text { Dry weight }(\text { after freeze drying })}{\text { Total weight }(\text { before freeze drying })} \times 100$

This method was modified from Tran et al. (2018). Freeze drying typically results in very little residual water remaining $(\sim 1-4 \%)$.

Protein Determination. The total sample as well as the top and bottom fractions of each sample following ultracentrifugation and freeze drying was evaluated for protein content. Protein was determined as nitrogen (conversion factor $=6.38$ ) using the Dumas combustion method (Chang and Zhang, 2017). Samples ( 0.10 g) were weighed into a tin foil cap and deposited into the instrument (Leco FP528, Leco Corp.) for combustion.

Crude Fat Determination. The total sample as well as the top and bottom fractions of each sample following ultracentrifugation and freeze drying was evaluated for crude fat content. Samples (0.1-0.3 g) were weighed into previously weighed filter bags and heatsealed. Fat was extracted with petroleum ether $\left(90^{\circ} \mathrm{C}\right.$, $60 \mathrm{~min}$ ) using an automated fat extractor (Method 2, Ankom XT15, Ankom Technology) as described by Tran et al. (2018). After extraction, the remaining petroleum ether was evaporated off in an oven $\left(105^{\circ} \mathrm{C}\right)$ for 30 min. Following drying, the samples were brought to room temperature and reweighed. Crude fat percentage was calculated as follows (Equation [2]):

Crude fat $(\%)=$

original sample weight $(\mathrm{g})$ - sample weight after extraction (g)

original sample weight

\section{Fat Crystallization and Melting Profile Characterization}

The fat crystallization profiles of the samples at $\mathrm{pH}$ 7.0 and samples at $\mathrm{pH} 5.0$ were determined using DSC. The instrument (DSC Q100, TA Instruments) was calibrated with indium before analysis. Freeze-dried samples $(\sim 3 \mathrm{mg})$ were added to aluminum pans before being subjected to the following DSC temperature program: starting temperature of $0^{\circ} \mathrm{C}$, heating at $1^{\circ} \mathrm{C} / \mathrm{min}$ to $60^{\circ} \mathrm{C}$, holding at $60^{\circ} \mathrm{C}$ for $10 \mathrm{~min}$ (elimination of fat crystalline behavior), cooling at $1^{\circ} \mathrm{C} / \mathrm{min}$ to $-40^{\circ} \mathrm{C}$ (fat crystallization), and heating at $1^{\circ} \mathrm{C} / \mathrm{min}$ to $60^{\circ} \mathrm{C}$ (fat melting). An empty pan was used as a reference. 


\section{Fat Molecular Mobility Evaluation}

A Bruker Minispec mq20 NMR Analyzer (Bruker Biosciences Espanola) was used to determine transverse relaxation times (i.e., T2 relaxation times). The nuclear magnetic resonance (NMR) operating frequency was 19.475 $\mathrm{MHz}$ with a pole gap of $33 \mathrm{~mm}$ and working temperature of $40^{\circ} \mathrm{C}$. The $90^{\circ}$ and $180^{\circ}$ pulse lengths were $4.16 \mu \mathrm{s}$ and $7.86 \mu \mathrm{s}$, respectively with 2 -s recycle delays. The equipment gain was set at $81 \mathrm{~dB}$, allowing for the signal intensity to be $\sim 80 \%$. The number of data points for fitting was set at 500 to allow for the collection of the complete signal. Before conducting any measurements, a daily check was performed to ensure the equipment was functioning properly, as directed by the manufacturer. All freeze-dried samples were added to 18 -mm-diameter tubes to a height of $1.5 \mathrm{~cm}$. The samples were thermally equilibrated in an oven set at $40^{\circ} \mathrm{C}$ (i.e., above the melting point of the fat used) for $1 \mathrm{~h}$ before measurement.

The t2_cp_mb application (Bruker) was used to monitor the decay of transverse magnetization and to calculate an overall transverse relaxation time value (defined as the time required for the transverse magnetization to fall to approximately $37 \%$ of its initial value). All samples were measured in triplicate with 5 scans per sample.

\section{Cryogenic Transmission Electron Microscopy (Cryo-TEM)}

Non-HPJ-treated model milk, $400 \mathrm{MPa}$-treated skim milk, and 400 MPa-treated model milk were observed using cryogenic transmission electron microscopy (Cryo-TEM), following the methods described by Hettiarachchi et al. (2018) with slight modifications. Samples were diluted 10-fold with distilled water before being added onto a glow-discharged perforated carbon film supported on a 200-mesh copper grid (Ted Pella). The grids were then vitrified in liquid ethane and transferred into a single-tilt cryoholder under liquid nitrogen. The samples were observed with an FEI Tecnai 12 BioTwin electron microscope $(120 \mathrm{kV}$; FEI Company), and $\sim 20$ representative images were taken with a Gatan Orius SC 1000 CCD camera (Gatan Inc.).

\section{Statistical Analysis}

All samples were produced in triplicate, and procedures were completed in a randomized order. Minitab software (version 18.1; Minitab LLC) was used to conduct a 1-way ANOVA with Tukey's test applied for mean comparisons. $P$-values less than 0.10 were deemed significant (indicated with $*$ in tables) and $P$-values less than 0.05 were deemed highly significant (indicated with $* *$ in tables).

\section{RESULTS AND DISCUSSION}

\section{Proximate Analysis of Total Samples and Ultracentrifuged Fractions}

The model milk samples were formulated to be $\sim 7 \%$ total solids with $\sim 41.4 \%$ protein dry basis and $\sim 51.4 \%$ fat dry basis. The non-HPJ-treated and 400 MPa-treated samples had $6.70 \pm 0.20 \%$ and $6.42 \pm$ $0.23 \%$ total solids, respectively. The dry solids were composed of $45.25 \pm 1.72 \%$ protein and $49.55 \pm 1.33 \%$ crude fat for the non-HPJ-treated sample and $45.90 \pm$ $1.54 \%$ protein and $43.77 \pm 1.54 \%$ crude fat for the 400 MPa-treated sample. As the samples were composed entirely of water $(93 \%)$, CBS $(3.6 \%)$, and MCC $(3.4 \%$, specified to be $86 \%$ protein dry basis), the remaining unaccounted-for dry weight consisted of lactose, ash, or fat that was not extracted using the crude fat extraction procedure. Neither the total solids content nor protein content were significantly different $(P=0.18$ and 0.65 , respectively) when comparing the non-HPJtreated and $400 \mathrm{MPa}$-treated model milks. However, the $400 \mathrm{MPa}$-treated sample exhibited significantly $(P=0.01)$ less total crude fat, which did not reflect an actual loss of fat (i.e., the total solids content was not significantly different) but rather that the crude fat extraction procedure was not sufficient to extract all of the fat in the fat-protein complex, as previously reported by Voronin et al. (2020).

Upon ultracentrifugation, milk typically separates into 3 layers: a top layer composed of the least dense components (i.e., fat), a middle layer composed of serum (i.e., lactose, minerals, whey proteins), and a bottom layer composed of the densest components (i.e., casein proteins). Without $\mathrm{pH}$ adjustment (i.e., $\mathrm{pH}$ 7.0), the non-HPJ-treated sample separated out into a fatty top layer $(0.33 \pm 0.02 \mathrm{~g}$, composed of $\sim 94 \%$ crude fat and $4 \%$ protein) and a proteinaceous bottom layer (0.51 \pm $0.04 \mathrm{~g}$, composed of $\sim 20 \%$ crude fat and $66 \%$ protein; Figure 2). In contrast, the $400 \mathrm{MPa}$-treated model milk at $\mathrm{pH} 7.0$, separated out into a small, fatty top layer $(0.08 \pm 0.01 \mathrm{~g}$ composed of $\sim 94.8 \%$ crude fat and $4.4 \%$ protein) and a thick, fat-containing bottom layer (0.93 $\pm 0.04 \mathrm{~g}$ composed of $\sim 42 \%$ crude fat and $48 \%$ protein; Figure 2). The bottom layer of the $400 \mathrm{MPa}-$ treated sample was much larger and had significantly $(P<0.01)$ more crude fat than the bottom layer of the non-HPJ-treated sample, suggesting that the fat was either entrapped or strongly interacting with the denser 
casein proteins, causing it to sink upon ultracentrifugation regardless of its intrinsically and comparatively low density. This is the fat-protein complex reported after similar HPJ treatment of various dairy products (Tran et al., 2018; Voronin et al., 2020).
Proximate Analysis of Total Samples

and Ultracentrifuged Fractions at $\mathrm{pH} 5.0$

Caseins aggregate when the $\mathrm{pH}$ reaches the isoelectric point (i.e., 4.6) as the electrostatic repulsive forces
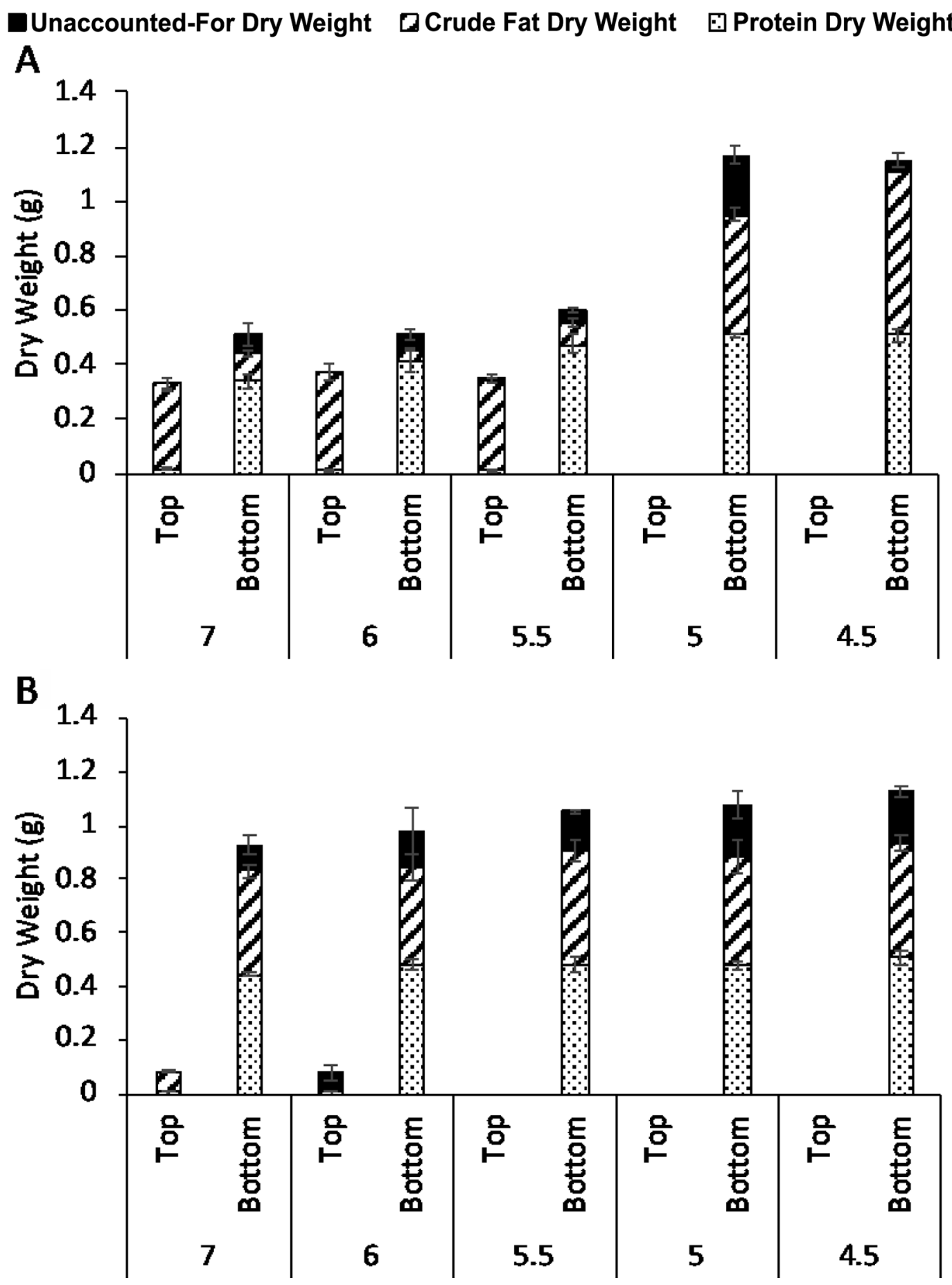

Figure 2. Proximate analysis of the top and bottom of non-high-pressure jet-treated (A) and 400 MPa-treated (B) model milk samples following $\mathrm{pH}$ alterations, ultracentrifugation, and freeze drying. Values are presented as mean $\pm \mathrm{SD}(\mathrm{n}=3) .7,6,5.5,5$, and 4.5 are the $\mathrm{pH}$ of the model milk samples. 
between proteins are lessened. The composition of the non-HPJ-treated and HPJ-treated model milk phases post-ultracentrifugation was studied as a function of $\mathrm{pH}$ (7.0-4.5). The composition of the phases of the nonHPJ-treated model milk did not change much until the $\mathrm{pH}$ reached 5.0 (Figure 2). However, at $\mathrm{pH} 5.0$ and below, a visible top layer was no longer visible upon ultracentrifugation of the non-HPJ-treated model milk, and, instead, all components (i.e., fat and protein) sedimented together, creating a thick bottom layer $(1.17 \pm$ $0.03 \mathrm{~g}$ ) composed of $\sim 44 \%$ protein and $38 \%$ crude fat. We hypothesize that lowering the $\mathrm{pH}$ toward the isoelectric point of casein decreased protein-protein electrostatic repulsion and allowed more of the dispersed casein to adsorb as secondary layers on fat droplets. The effective density of the particles increased as more protein adsorbed and eventually became greater than that of the serum, causing the droplet to sediment on ultracentrifugation.

As the $\mathrm{pH}$ of the $400 \mathrm{MPa}$-treated model milk was reduced, more solids $(1.13 \pm 0.02 \mathrm{~g}$ at $\mathrm{pH} 4.5$ vs. 0.93 $\pm 0.04 \mathrm{~g}$ at $\mathrm{pH} 7.0$ ) fell to the bottom layer upon ultracentrifugation, with the percentage of crude fat in the bottom layer being $\sim 38 \%$ at $\mathrm{pH} 4.5$ compared with $\sim 42 \%$ at $\mathrm{pH}$ 7.0. For the HPJ-treated model milk, acidinduced coagulation of the fat-protein complex seemed to entrap all remaining "free-fat" in the system (i.e., the little fat that rose to the top after the ultracentrifugation of $400 \mathrm{MPa}$-treated model milk at $\mathrm{pH}$ 7.0).

Overall, whereas the fat in non-HPJ-treated model milk only sedimented at low $\mathrm{pH}$, most of the fat in HPJ-treated model milk sedimented at $\mathrm{pH}$ 7.0. The small fraction of fat that creamed in HPJ-treated milk at $\mathrm{pH} 7.0$ may have a structure similar to the fat in the non-HPJ-treated model milks (i.e., only sedimented when the $\mathrm{pH}$ was lowered, as more casein adsorbed onto the fat droplets).

\section{Crystallization and Melting of Fat at $\mathrm{pH} 7.0$}

The crystallization peaks of freeze-dried non-HPJtreated model milks and $400 \mathrm{MPa}$-treated model milks are shown in Figure 3. The quantification of the crystallization onset, peak maxima, and conclusion is shown in Table 1.

The pure CBS had one clear peak with a maximum at $17.88^{\circ} \mathrm{C}$ (Figure 1). The non-HPJ-treated model milk had one broad crystallization peak that reached 2 local maxima at $17.34 \pm 2.00^{\circ} \mathrm{C}$ (peak no. 1 ) and 9.99 $\pm 0.31^{\circ} \mathrm{C}$ (peak no. 2). The $400 \mathrm{MPa}$-treated model milk had 2 distinct crystallization peaks that reached 3 local maxima at $18.86 \pm 0.38^{\circ} \mathrm{C}$ (peak no. 1 ), $5.35 \pm$ $0.18^{\circ} \mathrm{C}$ (peak no. 2 ), and $-1.25 \pm 0.08^{\circ} \mathrm{C}$ (peak no. 3 ), respectively.
Peak 1 of the $400 \mathrm{MPa}$-treated sample, the nonHPJ-treated sample, and the single peak from bulk fat (Figure 1) all initiated and reached local maxima at similar temperatures, so they were likely due to the crystallization of populations of fat with similar nucleation properties to bulk fat. The other populations of fat (i.e., peak 2 and peak 3) in the non-HPJ-treated and HPJ-treated model milks must have a different structure than the bulk fat, making them less prone to crystallization.

Truong et al. (2014) showed that cooling rate, emulsifier type, and emulsion droplet particle size affected the crystallization patterns of fractionated anhydrous milkfat. Truong et al. (2014) concluded that as fats are divided into smaller droplets, more catalytic impurities are required to initiate crystallization, so smaller fat droplets often require deeper supercooling. Additionally, other reports have shown that protein-fat interactions change fat crystallization (Santosa and Padua, 2000; Lodha and Netravali, 2005; de la Caba et al., 2012). In the present experiment, cooling rate was held constant $\left(1^{\circ} \mathrm{C} / \mathrm{min}\right)$. Therefore, either reduced fat droplet size or nonspecific fat-casein interactions explain the lower crystallization temperature of peaks 2 and 3 for the non-HPJ and HPJ-treated model milks. The non-HPJ-treated model milks were homogenized at low pressure $(\sim 15 \mathrm{MPa})$; therefore, the peak with delayed crystallization onset (i.e., peak 2) was probably due to particle size reduction. On the other hand, the influence of the extreme physical stresses of HPJ processing on dairy systems could induce more severe fat particle size reduction and fat-casein interactions than traditional homogenization; therefore, the peaks with reduced crystallization onset in the HPJ-treated model milks (i.e., peak 2 and 3) could be due to either fat particle size reduction or nonspecific casein-fat interactions.

The melting peaks of the freeze-dried non-HPJtreated model milks and $400 \mathrm{MPa}$-treated model milks at $\mathrm{pH} 7.0$ are shown in Figure 4. The quantification of the melting onset, peak, and conclusion at $\mathrm{pH} 7.0$ is reported in Table 1. Unlike with crystallization, the shape of the melting peaks for the non-HPJ-treated and $400 \mathrm{MPa}$-treated model milks were similar, with no significant differences between the peak maximum $(P=$ $0.35)$ or conclusion $(P=0.64)$.

\section{Crystallization of Fat at $\mathrm{pH} 5.0$}

The fat co-precipitated with casein proteins upon ultracentrifugation in both the non-HPJ-treated and 400 MPa-treated model milks when the $\mathrm{pH}$ was brought to 5.0 (Figure 2). By performing DSC on the non-HPJtreated and $400 \mathrm{MPa}$-treated model milks at $\mathrm{pH}$ 5.0, we 


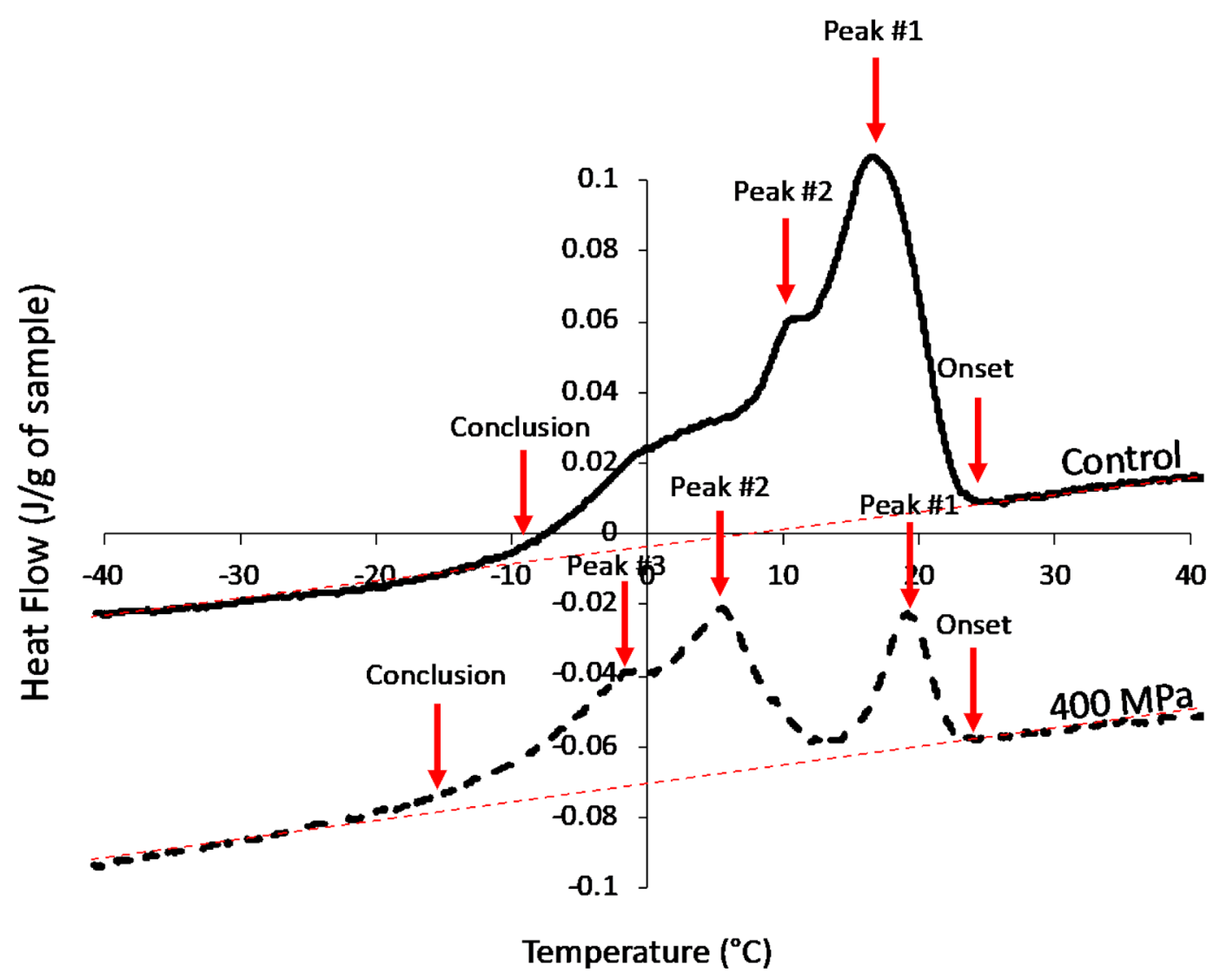

Figure 3. Fat crystallization profile of non-high-pressure jet-treated (control) and $400 \mathrm{MPa}$-treated model milks at pH 7.0. Arrows represent the reported values for crystallization onset, peak maxima, and conclusion (from right to left). The red dotted line indicates the baseline that was used to determine crystallization onset, conclusion, and enthalpy. This thermogram was a cooling run $\left(1^{\circ} \mathrm{C} / \mathrm{min}\right) \mathrm{with}$ the exothermic reaction pointing up.

wanted to determine whether any changes to the nature of the fat in these systems occurred upon acidification. The crystallization profile of these samples is presented in Figure 5, and the quantification of the crystallization profiles is presented in Table 1.
Relatively minor changes to the crystallization profile of non-HPJ-treated milk occurred when the $\mathrm{pH}$ was reduced from 7.0 (Figure 3) to 5.0 (Figure 5), as a clear secondary maximum no longer appeared, but a shoulder was still observable at the side of the major

Table 1. Fat crystallization and melting onset, peak maxima, conclusion, and enthalpy values $( \pm \mathrm{SD})$

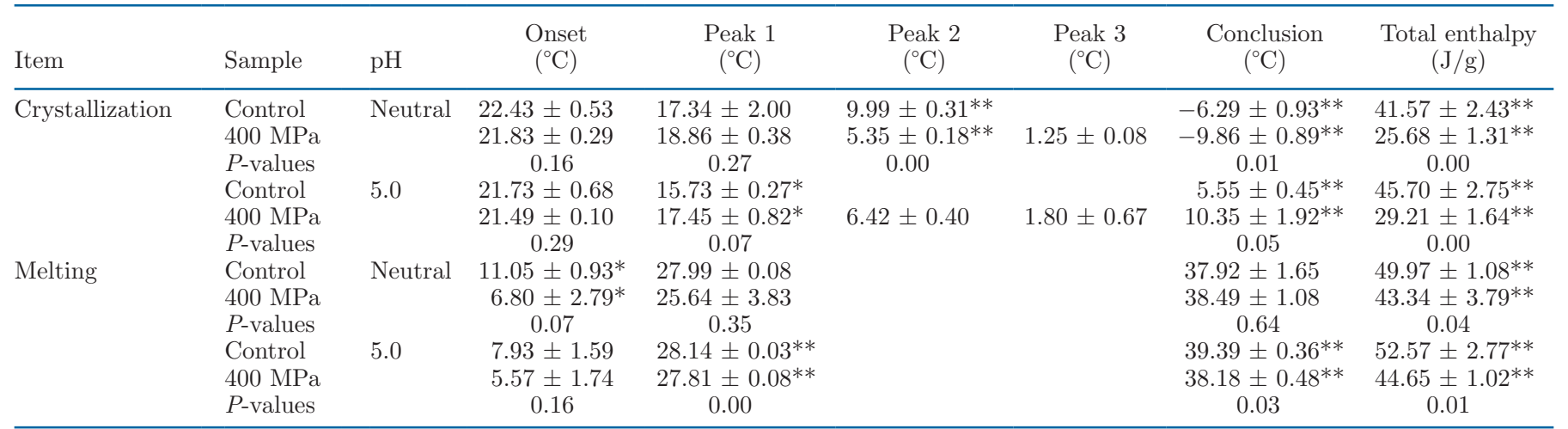

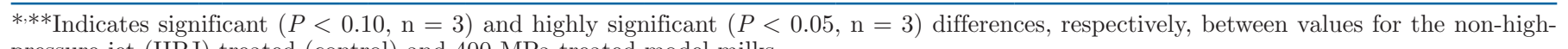
pressure jet (HPJ)-treated (control) and $400 \mathrm{MPa}$-treated model milks. 


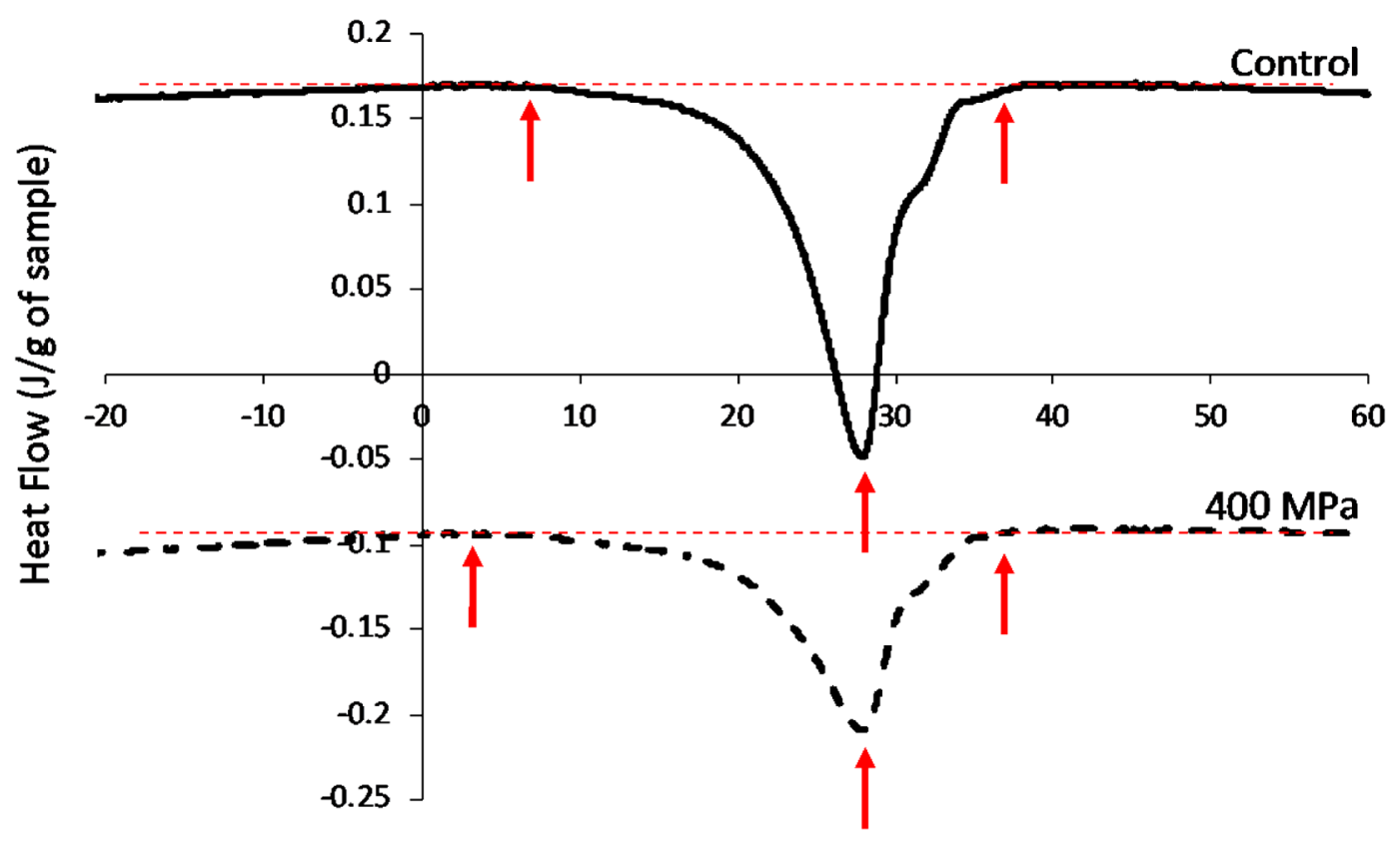

Temperature $\left({ }^{\circ} \mathrm{C}\right)$

Figure 4. Fat melting profile of non-high-pressure jet-treated (control) and $400 \mathrm{MPa}$-treated model milks at pH 7.0. Arrows represent the reported values for melting onset, peak maximum, and conclusion (from left to right). The red dotted line indicates the baseline that was used to determine crystallization onset, conclusion, and enthalpy. This thermogram was a heating $\mathrm{run}\left(1^{\circ} \mathrm{C} / \mathrm{min}\right)$ with the exothermic pointing up.

peak. Similarly, no change in the crystallization profile of the $400 \mathrm{MPa}$-treated model milk occurred as $\mathrm{pH}$ was reduced. This suggests that, despite acidification changing the effective density of the droplets and making them sink rather than float, the tendency for the fat to crystallize, and hence the droplet size, was unchanged. The droplets may have aggregated, or more protein may have accumulated at the surfaces of the fat droplets, but the size of the fat droplets themselves was unchanged.

\section{Enthalpy of Fat Crystallization and Melting at $\mathrm{pH} 7.0$ and $\mathrm{pH} 5.0$}

The total crystallization enthalpy of the $400 \mathrm{MPa}-$ treated model milk was $\sim 61.8 \%$ and $63.9 \%$ of the non-HPJ-treated model milk at $\mathrm{pH} 7.0$ and $\mathrm{pH} 5.0$, respectively $(P<0.01$ for both, Table 1$)$. The melting enthalpy of the $400 \mathrm{MPa}$-treated model milk was also significantly lower than the non-HPJ-treated model milk at both $\mathrm{pH} 7.0$ and $\mathrm{pH} 5.0(P=0.04$ and 0.01 , respectively), equating to $\sim 86.7 \%$ and $84.9 \%$ of the enthalpy of the non-HPJ-treated sample at $\mathrm{pH} 7.0$ and 5.0 , respectively. That is to say, less heat was released during crystallization, and somewhat less heat was absorbed during melting in the HPJ-treated model milks compared with non-HPJ-treated model milks. This could be due to (1) more liquid fat remaining dispersed throughout the cooling cycle in the HPJ-treated sample or (2) the fat crystals in the HPJ-treated sample being in a less stable polymorphic form.

(1) It is possible that some oil remained liquid during the cooling cycle because it was in a form with even less tendency to nucleate, presumably in very small droplets. Although the possibility of single triglycerides interacting with dispersed casein proteins cannot be discounted, some limit to the fat droplet sizes would likely be possible, as very fine droplets would be highly prone to Ostwald ripening, and an aqueous protein matrix would not provide a barrier to the diffusion of solubilized triacylglycerol molecules.

(2) Fat can typically crystallize into different polymorphic forms with ranging stabilities and shapes. Although we do not know the polymorphic forms of the fat used in this experiment (i.e., CBS), we can consider the most common and well-studied fat crystal polymorphic forms (i.e., $\alpha-, \beta^{\prime}-$, and $\beta$-crystals) to give insight into our system. That is, $\alpha$ - and $\beta^{\prime}$-crystals (i.e., the less stable crystal polymorphs) tend to reorganize themselves into 
the stable $\beta$-polymorph with storage and heating (Bunjes et al., 2003). However, if $\alpha$-crystals are held within nanoparticles with a rigid enough curvature at the surface, they remain stable and do not reorganize into $\beta$-crystals for extended periods of time (Joseph et al., 2015). Therefore, considering the reduced enthalpy of the 400 MPa-treated model milk, it is possible that a population of fat in this system crystallizes in a less stable polymorphic form (not necessarily the $\alpha$-crystal form) compared with the fat in the non-HPJ-treated model milk, releasing less energy upon crystallization. Furthermore, it is possible that, despite the amount of time held under freezing conditions, a population of fat in the $400 \mathrm{MPa}$-treated model milk was unable to realign into the more stable form (presumably due to the fat being held in very small domains); therefore, the enthalpy of melting was still lower than the non-HPJ-treated model milk.
Both of these mechanisms are consistent with the hypothesis that HPJ processing produces nanoscale fat domains, or that fat is not available for crystallization or melting due to protein complexation, or both.

\section{Characterization of Fat Molecular Mobility Using Time-Domain NMR}

Time-domain NMR can be used to evaluate the relaxation behavior of a sample in 3 steps (Kirtil and Oztop, 2016). First, a sample held in a permanent magnetic field, allowing for alignment of proton spins in-phase with the magnetic field. Then, the sample is disturbed by a brief secondary magnetic signal perpendicular to the permanent field, shifting the proton spins $90^{\circ}$. Finally, the relaxation of the sample signal to its initial state (i.e., aligned with the permanent magnetic field) is monitored, allowing for determination of the transverse relaxation behavior. The speed at which protons realign with the initial magnetic field is indicative

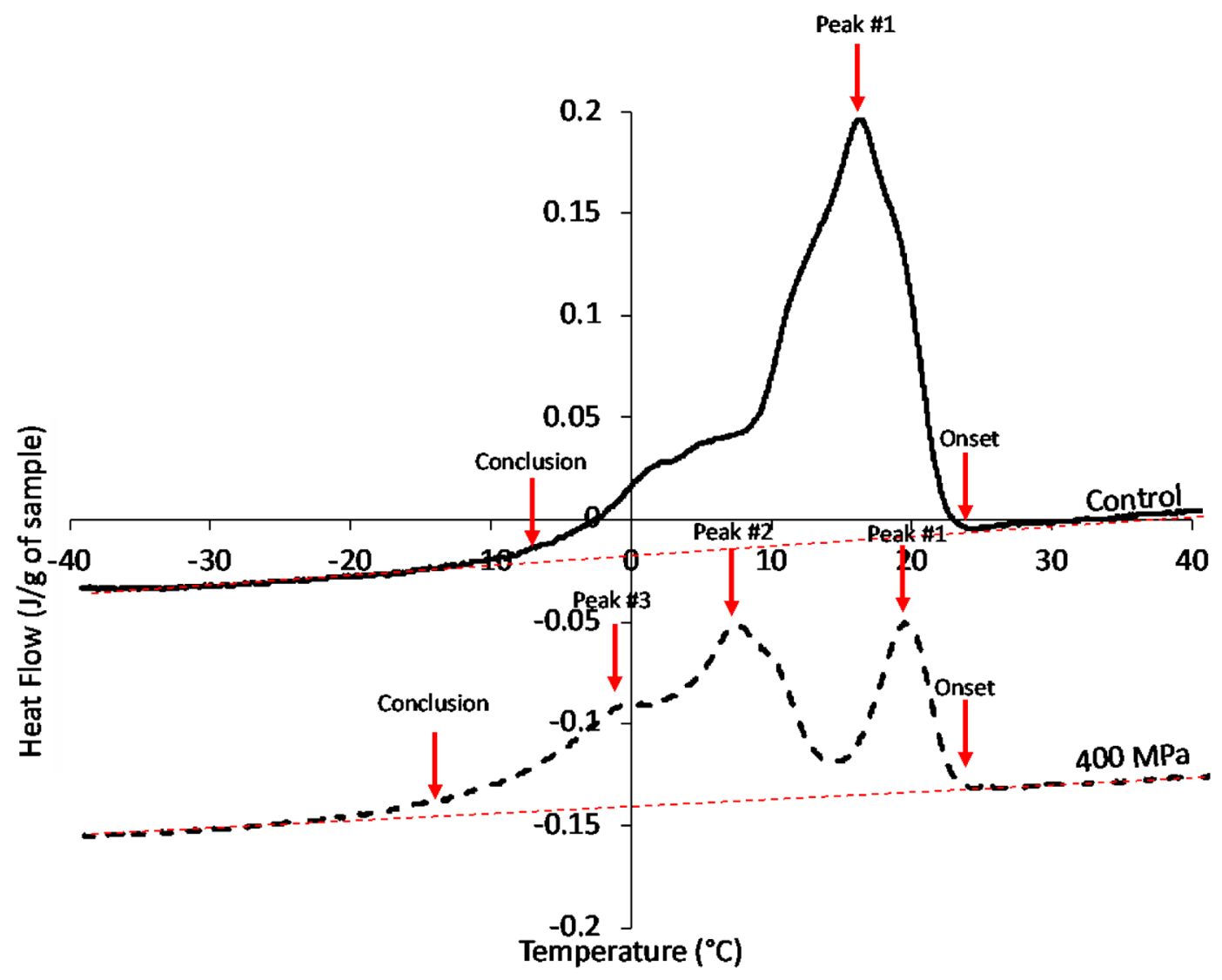

Figure 5. Fat crystallization profile of non-high-pressure jet-treated (control) and $400 \mathrm{MPa}$-treated model milks at pH 5.0. Arrows represent the reported values for crystallization onset, peak maxima, and conclusion (from right to left). The red dotted line indicates the baseline that was used to determine crystallization onset, conclusion, and enthalpy. This thermogram was a cooling run $\left(1^{\circ} \mathrm{C} / \mathrm{min}\right)$ with the exothermic reaction pointing up. 
of their molecular mobility, with more mobile protons (e.g., protons of fat and water) having slower relaxation times compared with semi-mobile protons with shorter relaxation times (e.g., protons of proteins).

Our system, where the samples were freeze-dried before analysis, was composed primarily of a protein component (containing semi-mobile protons with relation times $0.05-2 \mathrm{~ms}$ ) and a fat component (containing mostly mobile protons with relation times $>2 \mathrm{~ms}$ ). With an echo time of $2 \mathrm{~ms}$, the semi-mobile protons of the proteins were ignored, ensuring that the observed signal came only from the mobile protons (i.e., fat). In this case, the fat was held at $40^{\circ} \mathrm{C}$ for $1 \mathrm{~h}$ before analysis, to ensure that the measured relaxation times corresponded to liquid fat and, therefore, was not related to the fat crystalline form. Considering this, time-domain NMR was used to elucidate the mobility of liquid fat in the non-HPJ-treated and $400 \mathrm{MPa}$-treated samples.

Pure fat had a relaxation time of $157.6 \mathrm{~ms}$, which was greater than that in the model milk samples. The 400 MPa-treated model milk had a significantly $(P=0.07)$ lower relaxation time than the non-HPJ-treated model milk at $\mathrm{pH} 7.0$ (Table 2).

A reduction in particle size often corresponds to a decrease in relaxation value due to a faster proton exchange (Kirtil and Oztop, 2016; Pocan et al., 2019). Additionally, the adsorption of emulsifiers at droplet interfaces alters the conformation of fat at the interface, restricting its mobility and decreasing its relaxation time (Le Botlan et al., 2000). Dispersed colloidal components in the continuous phase (i.e., fat) can also restrict the mobility of the continuous phase and lead to shorter relaxation times (Kirtil and Oztop, 2016; Pocan et al., 2019). In the present work, it is possible that the decreased relaxation times of the fat in the $400 \mathrm{MPa}$-treated model milks were due to (1) the fat being held in smaller domains or (2) more of the fat in small domains interacting with proteins adsorbed to the surface. Although neither of these possibilities can be eliminated, the relaxation results support our earlier interpretation from the DSC work that the fat droplets are held in very small domains (i.e., nanoparticles) due to the HPJ-induced disruption and subsequent reaggregation of casein and fat in the $400 \mathrm{MPa}$-treated model milk.

\section{Visualization of "Fat-Protein Complexes"}

Both DSC and time-domain NMR suggest that a 400 $\mathrm{MPa}$ HPJ treatment isolated fat in very small domains. Although fat cannot be directly distinguished using cryo-TEM, the intricate structure of protein aggregates can be visualized, and, if fat was incorporated into
Table 2. Relaxation (T2) values $( \pm \mathrm{SD})$ for non-high-pressure jet (HPJ)-treated (control) and $400 \mathrm{MPa}$-treated model milks at neutral $\mathrm{pH}$ and $\mathrm{pH} 5.0$

\begin{tabular}{llc}
\hline Sample & $\mathrm{pH}$ & $\mathrm{T} 2(\mathrm{~ms})$ \\
\hline Control & Neutral & $125.2 \pm 5.9^{*}$ \\
$400 \mathrm{MPa}$ & & $103.7 \pm 13.8^{*}$ \\
$P$-value & & 0.07 \\
Control & 5.0 & $138.3 \pm 0.7^{* *}$ \\
$400 \mathrm{MPa}$ & & $123.7 \pm 1.7^{* *}$ \\
$P$-value & & 0.00
\end{tabular}

*,**Indicates significant $(P<0.10, \mathrm{n}=3)$ and highly significant $(P$ $<0.05, \mathrm{n}=3$ ) differences, respectively, between values for the nonhigh-pressure jet (HPJ)-treated (control) and $400 \mathrm{MPa}$-treated model milks.

these protein aggregates, it would appear as differential density on the micrographs. To test this, 3 samples were analyzed using cryo-TEM: (1) non-HPJ-treated model milk, (2) HPJ-treated skim milk, and (3) HPJ-treated model milk. These images are shown in Figure 6.

Visualization of non-HPJ-treated model milk using cryo-TEM was used as a baseline of casein micelle density without fat incorporation, as fat would exist in domains separate from casein micelles in this sample. In the non-HPJ-treated model milk, the casein micelles seemed to be intact, as they appeared spherical and relatively dense, with visible microstructure (Figure $6.1 \mathrm{a}, \mathrm{b})$. In the non-HPJ-treated model milk, fat cannot be differentiated from background noise, as it is not incorporated into the casein micelles.

Visualization of HPJ-treated skim milk (containing minimal milkfat) using cryo-TEM was used to act as a density baseline for HPJ-induced casein disruption and reaggregation without the presence of fat. In the HPJ-treated skim milk, the $400 \mathrm{MPa}$ HPJ treatment disrupted the casein micelle, resulting in protein that reaggregated into regions of denser protein, without intricate internal structure, as well as regions of looser nondescript aggregates (Figure 6.2a, b).

Finally, the density of the cryo-TEM micrographs of the HPJ-treated model milk was compared with the non-HPJ-treated model milk and HPJ-treated skim milk, to provide insight into the location of fat domains. When fat was present in milk before HPJ treatment (i.e., in the HPJ-treated model milk), the final aggregates were less dense than the HPJ-treated skim milk, with no regions of dense protein visible nor any visible voids that could represent a moderately sized fat domain (Figure 6.3a, b). This heterogeneous density of protein in Figure 3b is consistent with the existence of fat nano-domains.

The ability to create fat nano-domains (i.e., nanoemulsions) has gained recent attention for use as delivery systems for hydrophobic molecules, including 

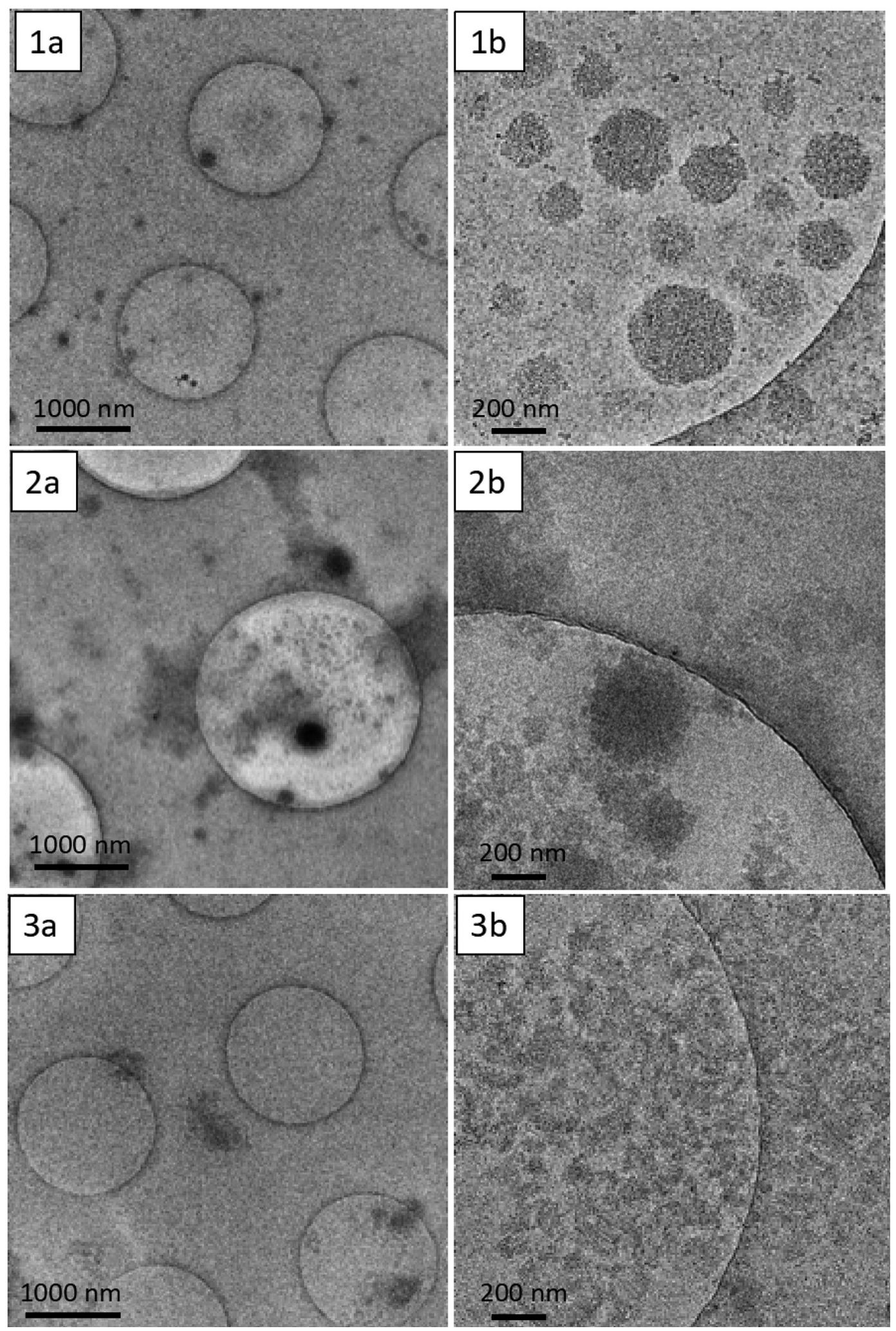

Figure 6. Non-high-pressure jet-treated model milk (1a, 1b), $400 \mathrm{MPa}$-treated skim milk (2a, 2b), and 400 MPa-treated model milk (3a, 3b) at 2 different magnifications. Uniform circles are the copper grid. 
nutraceuticals (Rao et al., 2013; Pinheiro et al., 2016; Rabelo et al., 2018; Salvia-Trujillo et al., 2019), vitamins (Saberi et al., 2014; Behjati and Yazdanpanah, 2021), and essential oils (Donsì and Ferrari, 2016). This study highlighted a method to produce caseinbased nanoemulsions for applications in the food and pharmaceutical industries. More work should be done to identify the exact size of fat domains within these nanoemulsions and to test specific industrial applications for these structures.

\section{CONCLUSIONS}

The structure of the "fat-protein complexes" formed with HPJ processing (400 MPa) was elucidated in this study by comparing the phase behavior, $\mathrm{pH}$ sensitivity, fat crystallization, relaxation behavior, and microstructure of non-HPJ-treated and 400 MPa-treated model milks. Observation of fat crystallization temperature indicated that populations of fat in $400 \mathrm{MPa}$-treated model milks were held within smaller domains or interacted with protein in a more substantial way than in non-HPJ-treated model milk. Even when crystallization was completed, the enthalpy of the crystallization process and melting process for the HPJ-treated model milk was not equivalent to that of a non-HPJ-treated model milk, indicating that fat in the HPJ-treated model milk was in less stable fat crystal polymorphic forms or even more resistant to crystallization. The properties of these lipid structures are largely independent of $\mathrm{pH}$, which suggests that their integrity depends on hydrophobic rather than electrostatic interactions between the proteins. This work better describes the HPJ-induced association between casein and fat in model dairy systems, allowing for more insight into the application of HPJ processing for the casein encapsulation of hydrophobic compounds for uses in the pharmaceutical and food industries.

\section{ACKNOWLEDGMENTS}

We sincerely thank Sung Hyun (Joseph) Cho (Department of Biochemistry and Molecular Biology, Pennsylvania State University, University Park, PA) for his expertise and help with the cryo-transmission electron microscopy work. We acknowledge the support of the National Dairy Council (Rosemont, IL) under the project "Transforming high pressure jet processing into a commercially viable technology for the dairy industry." This project was partially funded by USDA National Institute of Food and Agriculture (Washington, DC) federal appropriations under project PEN04565 and accession number 1002916. The authors have not stated any conflicts of interest.

\section{REFERENCES}

Behjati, J., and S. Yazdanpanah. 2021. Nanoemulsion and emulsion vitamin $\mathrm{D}_{3}$ fortified edible film based on quince seed gum. Carbohydr. Polym. 262:117948. https://doi.org/10.1016/j.carbpol.2021 .117948 .

Bunjes, H., M. H. J. Koch, and K. Westesen. 2003. Influence of emulsifiers on the crystallization of solid lipid nanoparticles. J. Pharm. Sci. 92:1509-1520. https://doi.org/10.1002/jps.10413.

Cano-Ruiz, M. E., and R. L. Richter. 1997. Effect of homogenization pressure on the milk fat globule membrane proteins. J. Dairy Sci. 80:2732-2739. https://doi.org/10.3168/jds.S0022-0302(97)76235 -0 .

Chang, S. K. C., and Y. Zhang. 2017. Protein analysis. Pages 315-331 in Food Analysis. S. S. Nielsen, ed. Springer International Publishing.

Cheema, M., A. N. Hristov, and F. M. Harte. 2017. The binding of orally dosed hydrophobic active pharmaceutical ingredients to casein micelles in milk. J. Dairy Sci. 100:8670-8679. https://doi.org/ $10.3168 /$ jds.2017-12631.

Datta, N., and P. M. Tomasula. 2015. Emerging Dairy Processing Technologies: Opportunities for the Dairy Industry. John Wiley \& Sons Inc.

de la Caba, K., C. Peña, E. M. Ciannamea, P. M. Stefani, I. Mondragon, and R. A. Ruseckaite. 2012. Characterization of soybean protein concentrate - Stearic acid/palmitic acid blend edible films. J. Appl. Polym. Sci. 124:1796-1807. https://doi.org/10.1002/app .35188 .

Donsì, F., and G. Ferrari. 2016. Essential oil nanoemulsions as antimicrobial agents in food. J. Biotechnol. 233:106-120. https://doi .org/10.1016/j.jbiotec.2016.07.005.

Haham, M., S. Ish-Shalom, M. Nodelman, I. Duek, E. Segal, M. Kustanovich, and Y. D. Livney. 2012. Stability and bioavailability of vitamin D nanoencapsulated in casein micelles. Food Funct. 3:737-744. https://doi.org/10.1039/c2fo10249h.

Harte, F. M. 2016. Food processing by high-pressure homogenization. Pages 123-141 in High Pressure Processing of Food: Principles, Technology and Applications. V. M. Balasubramaniam, G. V. Barbosa-Cánovas, and H. L. M. Lelieveld, ed. Springer New York.

Hettiarachchi, C. A., M. Corzo-Martínez, M. S. Mohan, and F. M. Harte. 2018. Enhanced foaming and emulsifying properties of highpressure-jet-processed skim milk. Int. Dairy J. 87:60-66. https:// doi.org/10.1016/j.idairyj.2018.06.004.

Joseph, S., M. Rappolt, M. Schoenitz, V. Huzhalska, W. Augustin. S. Scholl, and H. Bunjes. 2015. Stability of the metastable $\alpha$-polymorph in solid triglyceride drug-carrier nanoparticles. Langmuir 31:6663-6674. https://doi.org/10.1021/acs.langmuir $.5 \mathrm{~b} 00874$.

Kiełczewska, K., K. Ambroziak, D. Krzykowska, and M. Aljewicz. 2021. The effect of high-pressure homogenisation on the size of milk fat globules and MFGM composition in sweet buttermilk and milk. Int. Dairy J. 113:104898. https://doi.org/10.1016/j.idairyj .2020 .104898 .

Kirtil, E., and M. H. Oztop. 2016. Characterization of emulsion stabilization properties of quince seed extract as a new source of hydrocolloid. Food Res. Int. 85:84-94. https://doi.org/10.1016/j .foodres.2016.04.019.

Le Botlan, D., J. Wennington, and J. C. Cheftel. 2000. Study of the state of water and oil in frozen emulsions using time domain NMR. J. Colloid Interface Sci. 226:16-21. https://doi.org/10.1006/jcis .2000 .6785 .

Lee, S. J., and J. W. Sherbon. 2002. Chemical changes in bovine milk fat globule membrane caused by heat treatment and homogenization of whole milk. J. Dairy Res. 69:555-567. https://doi.org/10 $.1017 /$ S002202990200571X.

Lodha, P., and A. N. Netravali. 2005. Thermal and mechanical properties of environment-friendly 'green' plastics from stearic acid modified-soy protein isolate. Ind. Crops Prod. 21:49-64. https:// doi.org/10.1016/j.indcrop.2003.12.006.

Mohan, M. S., R. Ye, and F. Harte. 2016. Initial study on high pressure jet processing using a modified waterjet on physicochemical 
and rennet coagulation properties of pasteurized skim milk. Int. Dairy J. 55:52-58. https://doi.org/10.1016/j.idairyj.2015.12.004.

Obeid, S., F. Guyomarc'h, G. Francius, H. Guillemin, X. Wu, S. Pezennec, M.-H. Famelart, C. Cauty, F. Gaucheron, and C. Lopez. 2019. The surface properties of milk fat globules govern their interactions with the caseins: Role of homogenization and $\mathrm{pH}$ probed by AFM force spectroscopy. Colloids Surf. B Biointerfaces 182:110363. https://doi.org/10.1016/j.colsurfb.2019.110363.

Pinheiro, A. C., M. A. Coimbra, and A. A. Vicente. 2016. In vitro behaviour of curcumin nanoemulsions stabilized by biopolymer emulsifiers-Effect of interfacial composition. Food Hydrocoll. 52:460-467. https://doi.org/10.1016/j.foodhyd.2015.07.025.

Pocan, P., E. Ilhan, and M. H. Oztop. 2019. Characterization of emulsion stabilization properties of gum tragacanth, xanthan gum and sucrose monopalmitate: A comparative study. J. Food Sci. 84:1087-1093. https://doi.org/10.1111/1750-3841.14602.

Rabelo, C. A. S., N. Taarji, N. Khalid, I. Kobayashi, M. Nakajima, and M. A. Neves. 2018. Formulation and characterization of waterin-oil nanoemulsions loaded with açaí berry anthocyanins: Insights of degradation kinetics and stability evaluation of anthocyanins and nanoemulsions. Food Res. Int. 106:542-548. https://doi.org/ 10.1016/j.foodres.2018.01.017.

Ranadheera, C. S., W. S. Liyanaarachchi, J. Chandrapala, M. Dissanayake, and T. Vasiljevic. 2016. Utilizing unique properties of caseins and the casein micelle for delivery of sensitive food ingredients and bioactives. Trends Food Sci. Technol. 57:178-187. https: //doi.org/10.1016/j.tifs.2016.10.005.

Rao, J., E. A. Decker, H. Xiao, and D. J. McClements. 2013. Nutraceutical nanoemulsions: Influence of carrier oil composition (digestible versus indigestible oil) on $\beta$-carotene bioavailability. J. Sci. Food Agric. 93:3175-3183. https://doi.org/10.1002/jsfa.6215.

Rudan, M. A., D. M. Barbano, M. R. Guo, and P. S. Kindstedt. 1998. Effect of the modification of fat particle size by homogenization on composition, proteolysis, functionality, and appearance of reduced fat Mozzarella cheese. J. Dairy Sci. 81:2065-2076.

Saberi, A. H., Y. Fang, and D. J. McClements. 2014. Stabilization of vitamin E-enriched nanoemulsions: Influence of post-homogenization cosurfactant addition. J. Agric. Food Chem. 62:1625-1633. https://doi.org/10.1021/jf404182b.

Salvia-Trujillo, L., S. Verkempinck, S. K. Rijal, A. Van Loey, T. Grauwet, and M. Hendrickx. 2019. Lipid nanoparticles with fats or oils containing $\beta$-carotene: Storage stability and in vitro digestibility kinetics. Food Chem. 278:396-405. https://doi.org/10.1016/ j.foodchem.2018.11.039.

Santosa, F. X. B., and G. W. Padua. 2000. Thermal behavior of zein sheets plasticized with oleic acid. Cereal Chem. 77:459-462. https: //doi.org/10.1094/CCHEM.2000.77.4.459.

Tran, M., R. Roberts, T. L. Felix, and F. M. Harte. 2018. Effect of high-pressure-jet processing on the viscosity and foaming properties of pasteurized whole milk. J. Dairy Sci. 101:3887-3899. https: //doi.org/10.3168/jds.2017-14103.

Truong, T., N. Bansal, R. Sharma, M. Palmer, and B. Bhandari. 2014. Effects of emulsion droplet sizes on the crystallisation of milk fat. Food Chem. 145:725-735. https://doi.org/10.1016/j.foodchem 2013.08.072.

Tunick, M. H., D. X. Ren, D. L. Van Hekken, L. Bonnaillie, M. Paul, R. Kwoczak, and P. M. Tomasula. 2016. Effect of heat and homogenization on in vitro digestion of milk. J. Dairy Sci. 99:4124-4139. https://doi.org/10.3168/jds.2015-10474.

Voronin, G. L., R. Roberts, T. L. Felix, J. N. Coupland, and F. M. Harte. 2020. Effect of high-pressure-jet processing on the physiochemical properties of low-fat ice cream mix. J. Dairy Sci. 103:6003-6014. https://doi.org/10.3168/jds.2019-17814.

Walstra, P. 1999. Dairy technology: Principles of milk properties and processes. Food Science and Technology. CRC Press.

Wang, Y., M. Liu, X. Qu, S. Wang, Z. Ma, R. Zhang, H. Li, X. Liu, and J. Yu. 2019. Changes in the fat globule membrane protein components of pasteurized milk caused by different homogenization conditions determined using a label-free proteomic approach. Lebensm. Wiss. Technol. 115:108430. https://doi.org/10.1016/j .lwt.2019.108430.

Zamora, A., V. Ferragut, B. Guamis, and A. J. Trujillo. 2012. Changes in the surface protein of the fat globules during ultra-high pressure homogenisation and conventional treatments of milk. Food Hydrocoll. 29:135-143. https://doi.org/10.1016/j.foodhyd.2012.02.012.

\section{ORCIDS}

G. Lewis (ํ) https://orcid.org/0000-0001-7620-5844

F. M. Harte @ https://orcid.org/0000-0001-6822-0083 